\title{
On the Segregation of Genetically Modified, Conventional and Organic Products in European Agriculture: A Multi-market Equilibrium Analysis
}

\author{
GianCarlo Moschini, Harun Bulut and Luigi Cembalo ${ }^{1}$
}

(Original submitted March 2005, revision received July 2005, accepted September 2005.)

\begin{abstract}
Evaluating the possible benefits of the introduction of genetically modified (GM) crops must address the issue of consumer resistance as well as the complex regulation that has ensued. In the European Union (EU), this regulation envisions the co-existence of GM food with conventional and quality-enhanced products, mandates the labelling and traceability of GM products and allows only a stringent adventitious presence of GM content in other products. All these elements are brought together within a partial equilibrium model of the EU agricultural food sector. The model comprises conventional, GM and organic food. Demand is modelled in a novel fashion, whereby organic and conventional products are treated as horizontally differentiated but GM products are vertically differentiated (weakly inferior) relative to conventional ones. Supply accounts explicitly for the land constraint at the sector level and for the need for additional resources to produce organic food. Model calibration and simulation allow insights into the qualitative and quantitative effects of the large-scale introduction of GM products in the EU market. We find that the introduction of $G M$ food reduces overall EU welfare, mostly because of the associated need for costly segregation of non-GM products, but the producers of quality-enhanced products actually benefit.
\end{abstract}

Keywords: biotechnology; differentiated demand; genetically modified crops; identity preservation; innovation; welfare.

JEL classifications: $Q 1, O 3$.

\footnotetext{
${ }^{1}$ GianCarlo Moschini is a professor of economics and Pioneer endowed chair in science and technology policy, Harun Bulut is a post-doctoral fellow, and Luigi Cembalo was a visiting scientist, all with the Department of Economics, Iowa State University, Ames, IA 50011, USA. E-mail: moschini@iastate.edu for correspondence. Moschini and Bulut developed, calibrated and simulated the model, and wrote the paper. Cembalo assembled the data used in the calibration. The support of the US Department of Agriculture, through a National Research Initiative grant, is gratefully acknowledged.
} 


\section{Introduction}

The advent of biotechnology in agriculture has resulted in momentous (and ongoing) adjustments in the agricultural and food sector. In only a few years, a large portion of the area cultivated to some basic commodities has been converted to planting of genetically modified (GM) crops. James (2005) reports that planting of GM crops reached 200 million acres in 2004 worldwide, virtually all of which comprised four commodities: corn, soyabean, cotton and canola (oilseed rape). The hallmark of these GM crops, relative to those from prior breeding programmes, is an exciting novel scientific approach: insertion of foreign genetic material that confers a specific attribute of great interest (such as herbicide or pest resistance). Somewhat paradoxically, the novelty of GM crops explains both the enthusiastic support of their proponents and the widespread consumer and public opposition that has hampered its adoption in a number of countries. Indeed, GM crop adoption has been confined to a limited number of countries (the United States, Argentina, Brazil, Canada and China accounted for $96 \%$ of total GM crop cultivation in 2004). Elsewhere, GM crop adoption has been slowed down or hampered by novel regulations, apparently in response to the aforementioned vigorous public opposition (Sheldon, 2002).

Although some earlier studies have documented sizeable efficiency gains attributable to new GM crops (Moschini et al., 2000; Falck-Zepeda et al., 2000), it has become clear that a major feature of this new technology deserves more careful scrutiny. Specifically, a section of consumers perceives food made from GM products as weakly inferior in quality relative to traditional food. But the mere introduction of GM crops means that, to deliver traditional GM-free food, additional costs must be incurred (relative to the pre-innovation situation). This is because the commoditybased production, marketing and processing system, long relied upon by the food industry, is not suited to avoid the commingling of GM and non-GM crops. To satisfy the demand for non-GM food, costly identity preservation (IP) and segregation activities are required. Thus, the innovation process has, in this context, brought about a new market failure, essentially an externality on the production of traditional food products (Fulton and Giannakas, 2004; Lapan and Moschini, 2004).

The public concern about GM products has affected the regulatory process in the European Union (EU), yielding a sweeping new framework that became operative in April 2004. The new system is meant to foster food safety, protect the environment, and ensure consumers' 'right to know', and it is centred on the notions of labelling and traceability (European Union, 2004). Specifically, the new EU regulations require that food and feed consisting of, or produced from, GM crops be clearly labelled as such and envision a system that guarantees full traceability of GM food (and feed) products put on the marketplace. ${ }^{2}$ Labelling is mandatory for food and feed produced from GM crops, including food from GM products even when it does not contain protein or DNA from the GM crop (e.g. beet sugar). The threshold for avoiding the GM label is quite stringent: only a $0.9 \%$ adventitious presence of (authorised) GM products in food is tolerated for a product marketed without a GM label.

Perhaps in recognition of the interdependence and externalities characterising GM crop adoption, the EU is developing measures aimed at the 'co-existence' of GM and non-GM agriculture (Commission of the European Communities, 2003). The

\footnotetext{
${ }^{2}$ As pointed out by a reviewer, traceability in the EU is actually being envisioned for all food and feed, whether or not of GM origin, pursuant to Regulation EC 178/2002.
}

(c) Blackwell Publishing Ltd. 2005 
following extensive quote clarifies the EU position on this matter (European Union, 2003). 'The issue of co-existence refers to the ability of farmers to provide consumers with a choice between conventional, organic and GM products that comply with European labelling and purity standards. Co-existence is not about environmental or health risks because only GM crops that have been authorized as safe for the environment and for human health can be cultivated in the EU. ... Co-existence is concerned with the potential economic loss through the admixture of GM and non-GM crops which could lower their value, with identifying workable management measures to minimize admixture and with the cost of these measures.'

Thus, the unintended economic implications of the introduction of GM crops are very much at the forefront here and motivate our study. Although the EU proposal contains detailed suggestions on measures deemed necessary to ensure co-existence, the scale of the economic problem at hand has not, to date, been analysed in a coherent economic model. Indeed, current models of the economic impacts of GM product adoption have either assumed that GM and non-GM products are equivalent (Falck-Zepeda et al., 2000; Moschini et al., 2000; Demont and Tollens, 2004) or that there are two qualitatively different products - one GM and one non-GM such that non-GM products are treated as one type of good (Desquilbet and Bullock, 2001; Fulton and Giannakas, 2004; Lapan and Moschini, 2004).

The latter approach does reveal some important insights into the economics of GM crop adoption, including the finding that the GM innovation, in the end, may not improve welfare (Moschini and Lapan, 2005). But existing models are not refined enough to assess the differential impact that GM adoption may have when pre-existing products are already differentiated. In particular, the co-existence issue explicitly indicates the need to allow for three distinct products (conventional, organic and GM). Furthermore, although it has been shown that the welfare impact of GM innovation is ambiguous, it is of interest to understand what market conditions lead to negative as opposed to positive welfare effects. In the context of a larger model that accommodates the three types of products singled out by the co-existence issue, such welfare effects are likely to depend on the interdependence between markets. More specific attention to such multi-market effects is warranted. ${ }^{3}$

In this article, we develop a modelling framework that extends previous work by considering the introduction of GM products in a system where two differentiated products already exist: 'conventional' food and 'quality-enhanced' food. In the empirical part of the paper, the latter is identified with 'organic' food. The notion of organic food refers to the products of regulated production processes that essentially forego the use of a range of chemical inputs (fertilisers, herbicides and pesticides) that are widely used in conventional agriculture. What specifically can be called 'organic' is a matter of national regulations, and the EU has its own rules and standards. ${ }^{4}$ In the EU, organic production accounts for about $3 \%$ of the utilised agricultural area (UAA). But the EU recognises that a large number of other food products can claim superior quality attributes. The identification of these products in the marketplace is promoted by EU regulations that established special

\footnotetext{
${ }^{3}$ As noted by a reviewer, a study that models GM adoption with organic and conventional products in a vertically differentiated products context is Giannakas and Yiannaka (2003).

${ }^{4}$ See the EU webpage on Organic Agriculture: http://europa.eu.int/comm/agriculture/qual/ organic/.
} 
labels such as Protected Designation of Origin (PDO), Protected Geographical Indication (PGI) and Traditional Speciality Guaranteed (TSG). ${ }^{5}$ Thus, although our model, strictly speaking, identifies the pre-GM differentiated food with organic food, hopefully, the results that we derive can be interpreted more generally to pertain to the broader set of quality products that Europeans claim as a distinguishing feature of their agriculture (Fishler, 2002).

A first contribution of the paper is to derive a model of differentiated food demand that is consistent with the stylised attribute of the problem at hand. Specifically, we derive a demand system that admits three food products: conventional food, organic food and GM food (in addition to a numéraire which can be thought of as an aggregate of all other goods). In our demand framework, organic and conventional food products are horizontally differentiated, whereas GM and non-GM food products are vertically differentiated. Specifically, the GM good is a weakly inferior substitute for the conventional food, and the model is specified in such a fashion that all the relevant parameters can be identified from observation of the pre-innovation equilibrium. The supply side similarly accounts explicitly for the production of two and three products (before and after the GM innovation, respectively). Quality enhancement of organic production is modelled as deriving from additional efforts supplied by producers. Equilibrium conditions account explicitly for the IP costs that are necessary after the introduction of GM products, and endogenise the price of land and the reward to the additional efforts supplied by farmers. The model is calibrated to replicate the observed data of EU agriculture, based on assumed values of some parameters. The solution of the model - for baseline parameter values as well as other alternatives - allows us to determine the qualitative and quantitative economic impacts of the possible large-scale adoption of GM crops in the EU.

\section{Modelling Strategy}

The post-innovation situation is qualitatively different in that it is affected by a type of externality (technically a non-convexity), namely the need for segregation of the pre-existing products. Because of that, analytical welfare results are bound to be inconclusive - an increase or a decrease in aggregate welfare are both possible. To proceed, we propose an explicit specification of demand and supply relations to capture some stylised facts of GM product innovation. Next, we calibrate the model such that the chosen parameters are consistent with generally accepted attributes of the agricultural sector and can replicate exactly the benchmark data set. By solving the model thus calibrated under various assumptions, we can then shed some light on both the qualitative and quantitative potential effects of large-scale GM product adoption on European agriculture.

A major issue in the GM policy debate concerns consumers' attitudes towards these new products (Boccaletti and Moro, 2000). In representing the demand side of the market, therefore, we allow for the fact that the three food products are perceived as differentiated by consumers. But we also want to capture some stylised facts about

\footnotetext{
${ }^{5}$ At present there are more than 600 food products in the EU that can claim such quality labels, although their importance in terms of market share (and ultimately in terms of land used) is not known. See http://europa.eu.int/comm/agriculture/foodqual/qualil_en.htm, the EU webpage on Quality Policy.
} 
consumer preferences with respect to these goods. Specifically, conventional food is deemed no worse than GM food - in the definition of Lapan and Moschini (2004), GM food is a 'weakly inferior' substitute for conventional food. It seems that individual preferences are also quite heterogeneous with respect to our other product, organic food. Although some consumers have a strong preference for organic food, often based on perceived health, environmental and animal-welfare considerations, other consumers may, ceteris paribus, prefer conventional food based on other quality attributes (such as appearance, integrity and taste). Thus, in particular, the assumption that conventional food is weakly inferior to organic food would seem untenable. Hence, we develop a demand framework whereby organic and conventional food products are 'horizontally differentiated', whereas GM and non-GM food products are 'vertically differentiated'. This novel approach, detailed in the section to follow, captures the main attributes of demand in our context in an effective way.

As for the supply side, an essential facet of the co-existence issue relates to the adjustments in production brought about by the innovation adoption, in particular, with regard to the welfare of farmers. Concerning the latter, in a purely competitive sector such as agriculture, returns to producers must be associated with the presence of some fixed factors of production. Land being the obvious such fixed factor, in our model, we represent the entire agricultural sector and assume that a given endowment of land that can be used to produce two outputs before GM innovation (conventional and organic products) and three outputs after GM innovation (conventional, organic and GM products). Furthermore, it is apparent that organic products command a sizeable price premium over conventional ones, although organic production only accounts for a small share of overall production. The modelling avenue that we postulate to account for such stylised facts is that organic production requires an additional input in the form of farmer-supplied effort, and that this extra labour input required has an upward-sloping supply. This is certainly consistent with the observation that organic production is typically more labour-intensive, with customised labour tasks substituting for inadmissible chemical inputs. Because this modelling strategy effectively suffices in discriminating conventional and organic production, we then proceed by assuming that land quality is homogeneous. ${ }^{6}$

Moving to equilibrium considerations, it is critical in this setting to represent the novel impacts of GM product introduction in the marketplace. This requires an explicit consideration of the costs of IP activities that are required, after innovation adoption, to supply non-GM products to the consumers who want them. Furthermore, here we distinguish between the cost of IP itself with the additional burden that may be imposed by specific product-labelling rules. Although food labelling, in general, serves the ultimate purpose of conveying useful information to consumers (Golan et al., 2000), mandating that the inferior product carry the GM label, as required by the recently approved EU rules, appears to do little in that regard. In particular,

\footnotetext{
${ }^{6} \mathrm{~A}$ reviewer questioned the descriptive relevance of this assumption for the EU. Although that concern is legitimate, we can defend our modelling assumption as an abstraction that implements the existence of the (undeniable) land constraint at the sector level and, when coupled with the additional effort requirement for organic production, provides an effective representation of the different supply responses of conventional and organic production. An alternative modelling strategy, that we considered but did not adopt, would be to postulate that land is heterogeneous, i.e. each unit of land has different suitability (i.e. yields) for the three possible outputs.
} 
requiring GM products to identify themselves via a label does not alleviate the cost of IP (to be borne by non-GM suppliers) that is necessary to provide consumers with (credible) non-GM food. Put another way, from an information economics point of view, it is the superior (i.e., non-GM) product that should carry the label. Thus, in our model, we distinguish between the effects of IP (of the superior products) and the impact of labelling and traceability requirements (on the inferior product). ${ }^{7}$

\section{The model}

Based on the foregoing, the demand, supply and equilibrium conditions of an agricultural and food sector before and after GM innovation are specified as follows.

\subsection{Demand}

Because it is widely accepted that such features of food demand arise from a collection of consumers who manifest widely differing attitudes towards organic and GM food, it is useful to derive aggregate demand explicitly from the specification of individual consumer preferences. To implement the notion of weakly inferior substitutes, we extend the vertical product differentiation model to the unit demand of Mussa and Rosen (1978) and Tirole (1988, Chap. 7). In that setting, one postulates a population of consumers with heterogeneous preferences concerning two goods (in addition to the numéraire) but in which all consumers agree that one good is no worse than the other, ceteris paribus. We generalise that framework by allowing one additional good, such that the individual agent utility function is defined over four goods: conventional food $q_{\mathrm{n}}$, organic food $q_{\mathrm{b}}$, GM food $q_{\mathrm{g}}$ and a composite good $y$ (the numéraire). ${ }^{8}$ Furthermore, consumers here are not restricted to buy one unit of the product but decide how much to purchase (in addition to which good to purchase). As in the standard vertical product differentiation model, preferences are assumed to be quasi-linear, such that the individual consumer's utility function has the following structure:

$$
U\left(y, q_{\mathrm{b}}, q_{\mathrm{n}}, q_{\mathrm{g}} \mid \theta\right)=y+u\left(\left(q_{\mathrm{n}}+\theta q_{\mathrm{g}}\right), q_{\mathrm{b}}\right),
$$

where the function $u(\cdot)$ is assumed to be concave, and $\theta$ is an individual parameter that characterises the heterogeneity of consumers vis-à-vis their preference for GM food relative to conventional food.

Note that, absent GM food, the utility function (apart from the numéraire) reduces to $u\left(q_{\mathrm{n}}, q_{\mathrm{b}}\right)$. Thus, conventional and organic foods are treated as imperfect substitutes, but with no presumption that one is uniformly better than the other for all consumers. On the contrary, to capture the fact that GM food is assumed to be a

\footnotetext{
${ }^{7}$ A final consideration worth noting is that the model we develop and solve is calibrated at the farm-gate level. Accordingly, the demand functions that we consider must be interpreted as derived demands. In addition to reflecting the nature of final EU consumer demand, such derived demands implicitly account for the (net) excess demand for EU products originating from the export market. Thus, although the model formally represents a closed economy sector, it is in fact consistent with an open economy setting.

${ }^{8}$ The subscript ' $n$ ' stands for normal, the subscript ' $b$ ' stands for biological (i.e., organic), and the subscript ' $\mathrm{g}$ ' stands for genetically modified product.
} 
weakly inferior substitute for the conventional food, we assume that the distribution of the corresponding parameter satisfies $\theta \in[0,1]$. In the foregoing specification, each individual consumer will consume two goods: either organic and conventional, or organic and GM, although the heterogeneity of consumers implies that, in aggregate, all three food types may be consumed. ${ }^{9}$

More specifically, the consumer will buy the GM good if and only if $p_{\mathrm{g}}<\theta p_{\mathrm{n}}$, whereas he or she would buy the conventional food if $p_{\mathrm{g}} \geq \theta p_{\mathrm{n}} .{ }^{10}$ So, let $Q \equiv q_{\mathrm{n}}+\theta q_{\mathrm{g}}$ and let $p_{Q} \in\left\{p_{\mathrm{n}}, p_{\mathrm{g}} / \theta\right\}$ denote the price of $Q$ that applies (depending on whether $q_{\mathrm{n}}$ or $q_{\mathrm{g}}$ is consumed). Now, consider the problem of choosing $Q$ and $q_{\mathrm{b}}$ with the utility function rewritten as $U=y+u\left(Q, q_{\mathrm{b}}\right)$. Then the optimality conditions for an interior solution are $u_{Q}\left(Q, q_{\mathrm{b}}\right)=p_{Q}$ and $u_{q_{\mathrm{b}}}\left(Q, q_{\mathrm{b}}\right)=p_{\mathrm{b}}$, which yield the individual demand functions $d_{Q}\left(p_{Q}, p_{\mathrm{b}}\right)$ and $d_{\mathrm{b}}\left(p_{Q}, p_{\mathrm{b}}\right)$.

As for the choice between $q_{\mathrm{n}}$ and $q_{\mathrm{g}}$, as discussed earlier, that will depend on how the price ratio $p_{\mathrm{g}} / p_{\mathrm{n}}$ relates to $\theta$. Individuals with $\theta \leq p_{\mathrm{g}} / p_{\mathrm{n}}$ will prefer the conventional product and thus buy

$$
q_{n}=d_{Q}\left(p_{\mathrm{n}}, p_{\mathrm{b}}\right), \quad q_{\mathrm{b}}=d_{\mathrm{b}}\left(p_{\mathrm{n}}, p_{\mathrm{b}}\right) \quad \text { and } \quad q_{g}=0 .
$$

Individuals with $\theta>p_{\mathrm{g}} / p_{\mathrm{n}}$ will prefer the GM product and buy

$$
q_{\mathrm{g}}=\frac{1}{\theta} d_{\mathrm{Q}}\left(\frac{p_{\mathrm{g}}}{\theta}, p_{\mathrm{b}}\right), \quad q_{\mathrm{b}}=d_{\mathrm{b}}\left(\frac{p_{\mathrm{g}}}{\theta}, p_{\mathrm{b}}\right) \quad \text { and } \quad q_{\mathrm{n}}=0 .
$$

Market demand functions are obtained by integrating over all types. Thus,

$$
\begin{gathered}
D_{\mathrm{n}}\left(p_{\mathrm{n}}, p_{\mathrm{g}}, p_{\mathrm{b}}\right)=\int_{0}^{p_{\mathrm{g}} / p_{\mathrm{n}}} d_{\mathrm{Q}}\left(p_{\mathrm{n}}, p_{\mathrm{b}}\right) \mathrm{d} F(\theta) \\
D_{\mathrm{g}}\left(p_{\mathrm{n}}, p_{\mathrm{g}}, p_{\mathrm{b}}\right)=\int_{p_{\mathrm{g}} / p_{\mathrm{n}}}^{1} \frac{1}{\theta} d_{\mathrm{Q}}\left(\frac{p_{\mathrm{g}}}{\theta}, p_{\mathrm{b}}\right) \mathrm{d} F(\theta) \\
D_{b}\left(p_{\mathrm{n}}, p_{\mathrm{g}}, p_{\mathrm{b}}\right)=\int_{0}^{p_{\mathrm{g}} / p_{\mathrm{n}}} d_{\mathrm{b}}\left(p_{\mathrm{n}}, p_{\mathrm{b}}\right) \mathrm{d} F(\theta)+\int_{p_{\mathrm{g}} / p_{\mathrm{n}}}^{1} d_{\mathrm{b}}\left(\frac{p_{\mathrm{g}}}{\theta}, p_{\mathrm{b}}\right) \mathrm{d} F(\theta),
\end{gathered}
$$

where $F(\theta)$ denotes the distribution function of consumer types.

To find explicit demand functions, we rely on a simple parameterisation that generalises the constant-elasticity demand framework. Specifically, the utility function is written as:

$$
u\left(Q, q_{\mathrm{b}}\right)=\left(\frac{\varepsilon}{\varepsilon-1}\right)(k)^{1 / \varepsilon}\left[Q^{\lambda}\left(q_{\mathrm{b}}\right)^{1-\lambda}\right]^{(\varepsilon-1) / \varepsilon},
$$

where the parameter $\lambda \in(0,1)$ controls the share between conventional and organic food, the parameter $\varepsilon>0 \quad(\varepsilon \neq 1)$ controls the overall food demand elasticity and the parameter $k>0$ controls the size of the market. Given this utility function, it is easily verified that the individual demand functions display constant elasticity, specifically,

\footnotetext{
${ }^{9}$ We assume that $u(q)$ is such that the consumer will buy some amount of one of the goods, and that income is sufficiently high so that an interior solution holds.

${ }^{10}$ The consumer is actually indifferent between the two varieties if the equality holds, but the technical (and, in equilibrium, inconsequential) assumption here is that, under equality, the conventional food is purchased.
} 


$$
\begin{gathered}
d_{Q}\left(p_{\mathrm{Q}}, p_{\mathrm{b}}\right)=k(\lambda)^{1-\lambda(1-\varepsilon)}(1-\lambda)^{-(1-\varepsilon)(1-\lambda)} \cdot\left(p_{\mathrm{Q}}\right)^{-1+\lambda(1-\varepsilon)}\left(p_{\mathrm{b}}\right)^{(1-\varepsilon)(1-\lambda)} \\
d_{\mathrm{b}}\left(p_{\mathrm{Q}}, p_{\mathrm{b}}\right)=k(\lambda)^{1-\lambda(1-\varepsilon)}(1-\lambda)^{-(1-\varepsilon)(1-\lambda)} \cdot\left(p_{\mathrm{Q}}\right)^{\lambda(1-\varepsilon)}\left(p_{\mathrm{b}}\right)^{-\varepsilon-\lambda(1-\varepsilon)}
\end{gathered}
$$

Finally, we need to make assumptions about the distribution of consumer types (i.e. the parameter $\theta$ ). To this end, we wish to allow for a fraction of consumers to be indifferent between conventional and GM products. Given the choice, such consumers would simply buy the less costly of the two goods. ${ }^{11}$ Thus, we specify a mixed distribution function $F(\theta)$ such that for a fraction $\phi \in(0,1)$ of consumers the type is $\theta=1$, whereas for the remaining consumers the type $\theta$ is uniformly distributed on $[0,1) .{ }^{12}$ Hence, the density $f(\theta) \equiv F^{\prime}(\theta)$ on $[0,1)$ is $f(\theta)=1-\phi$.

Given this and the individual demands in equations (8)-(9), evaluating the integrals in equations (4)-(6), for the case $p_{\mathrm{n}}>p_{\mathrm{g}}$, we obtain:

$$
\begin{gathered}
D_{\mathrm{n}}\left(p_{\mathrm{n}}, p_{\mathrm{g}}, p_{\mathrm{b}}\right)=d_{\mathrm{Q}}\left(p_{\mathrm{n}}, p_{\mathrm{b}}\right)(1-\phi)\left(\frac{p_{\mathrm{g}}}{p_{\mathrm{n}}}\right) \\
D_{\mathrm{g}}\left(p_{\mathrm{n}}, p_{\mathrm{g}}, p_{\mathrm{b}}\right)=d_{\mathrm{Q}}\left(p_{\mathrm{g}}, p_{\mathrm{b}}\right)\left[\phi+A\left(p_{\mathrm{n}}, p_{\mathrm{g}}\right)\right] \\
D_{\mathrm{b}}\left(p_{\mathrm{n}}, p_{\mathrm{g}}, p_{\mathrm{b}}\right)=d_{\mathrm{b}}\left(p_{\mathrm{n}}, p_{\mathrm{b}}\right)(1-\phi)\left(\frac{p_{\mathrm{g}}}{p_{\mathrm{n}}}\right)+d_{\mathrm{b}}\left(p_{\mathrm{g}}, p_{\mathrm{b}}\right)\left[(1-\phi) A\left(p_{\mathrm{n}}, p_{\mathrm{g}}\right)+\phi\right],
\end{gathered}
$$

where $d_{Q}\left(\cdot, p_{\mathrm{b}}\right)$ and $d_{\mathrm{b}}\left(\cdot, p_{\mathrm{b}}\right)$ are given by equations (8) and (9), and

$$
A\left(p_{\mathrm{n}}, p_{\mathrm{g}}\right) \equiv \frac{(1-\phi)}{(1-\lambda(1-\varepsilon))}\left[1-\left(\frac{p_{\mathrm{g}}}{p_{\mathrm{n}}}\right)^{[1-\lambda(1-\varepsilon)]}\right] \text {. }
$$

For the case $p_{\mathrm{n}} \leq p_{\mathrm{g}}$, as noted earlier, $D_{\mathrm{g}}\left(p_{\mathrm{b}}, p_{\mathrm{n}}, p_{\mathrm{g}}\right)=0$. Such a case describes the situation prior to the introduction of GM food, where $D_{\mathrm{g}}=0$ and the demands for conventional and organic food reduce to

$$
\begin{aligned}
& D_{\mathrm{n}}\left(p_{\mathrm{n}}, p_{\mathrm{g}}, p_{\mathrm{b}}\right)=d_{\mathrm{Q}}\left(p_{\mathrm{n}}, p_{\mathrm{b}}\right) \\
& D_{\mathrm{b}}\left(p_{\mathrm{n}}, p_{\mathrm{g}}, p_{\mathrm{b}}\right)=d_{\mathrm{b}}\left(p_{\mathrm{n}}, p_{\mathrm{b}}\right),
\end{aligned}
$$

where, again, the functions $d_{Q}\left(\cdot, p_{\mathrm{b}}\right)$ and $d_{\mathrm{b}}\left(\cdot, p_{\mathrm{b}}\right)$ are as defined in equations (8) and (9). Note that the demand structure for the new product is described in terms of the same underlying preference parameters $(k, \varepsilon$ and $\lambda)$, a feature that is particularly convenient at the calibration and simulation stage.

\subsection{Production and supply}

To capture the essential elements of the co-existence issue for the supply side, as discussed earlier, we model the entire agricultural sector and assume that there is a

\footnotetext{
${ }^{11}$ Indeed, a good share of agricultural production is used as animal feed and, as noted by Brookes (2004), such a demand is probably indifferent as to whether the feed is GM or not.

${ }^{12}$ The parameter $\phi$ may also capture stylised facts about consumers' handling of label information (Noussair et al., 2002). One could also postulate the existence of a fraction of consumers for whom $\theta=0$. But imperfect information uptake from labels would spread this group, justifying the continuous distribution that we have postulated on $[0,1)$.
} 
given endowment of land that can be used to produce two outputs before GM innovation (conventional and organic products) and three outputs after GM innovation (conventional, organic and GM products). To keep things as simple and transparent as possible for the purpose of calibration, and yet obtain non-trivial outcomes at the policy analysis stage, we assume constant returns to scale (at the industry level) for both conventional and GM production. Specifically, if $x_{\mathrm{n}}$ denotes production of conventional food, $\pi$ is the unit rental price of land, and $w$ is the vector of prices of the intermediate inputs used in food production, the cost function can be written as:

$$
C^{\mathrm{n}}\left(x_{\mathrm{n}}, w, \pi\right)=x_{\mathrm{n}}\left[\alpha_{\mathrm{n}} \pi+c^{\mathrm{n}}(w)\right]
$$

where $\alpha_{\mathrm{n}}$ is a parameter that can be interpreted as the reciprocal of yield, and $c^{\mathrm{n}}(w)$ is an increasing, linearly homogeneous and concave function of prices. Note that this cost function is dual to a production function with a fixed proportion between land and a function of the bundle of market inputs (unrestricted substitutability between market inputs is thus allowed).

Production of organic food, on the contrary, is assumed to require three types of inputs: land, market-supplied inputs and farmer-supplied effort. Again, we assume fixed proportions between land, a function of the bundle of market supply inputs and farmer-supplied effort measured in some efficiency units. But, for the latter, we assume that the cost of drawing the required farmer-supplied efforts into organic production increases at the margin. For instance, one can imagine a population of potential organic farmers, each with its own reservation price to enter this particular industry (the heterogeneity displaying different abilities for supplying the effort required in organic food production). If $x_{\mathrm{b}}$ denotes the production of organic food, the corresponding cost function is written as:

$$
C^{\mathrm{b}}\left(x_{\mathrm{b}}, w, \pi\right)=x_{\mathrm{b}}\left[\alpha_{b} \pi+c^{\mathrm{b}}(w, z)\right]
$$

where $\alpha_{\mathrm{b}}$ is the parameter representing the reciprocal of yield, $z$ is a variable that indexes farmer-supplied inputs used in organic food production, and $c^{\mathrm{b}}(w, z)$ is increasing, linearly homogeneous, and concave in $w$, and increasing in $z$ (more on this to follow).

We measure conventional food and organic food in the same units. Typically, the presumption is that production per unit of land (i.e. yield) is lower in organic food production, which would imply $\alpha_{\mathrm{b}}>\alpha_{\mathrm{n}}$. Furthermore, we assume that the price vector $w$ of the intermediate inputs is given, and thus we subsume its effect in the unit sub-costs. Specifically, for the conventional product, we write $c^{\mathrm{n}}(w) \equiv c$ such that (for given $\pi$ and $w$ ) conventional food production is a constant marginal cost industry. Organic production, on the contrary, is assumed to be an increasing cost industry: at the margin, expanding organic production requires additional farmersupplied inputs that are available only at increasing cost. To capture that, and still take all market prices as given, we write $c^{\mathrm{b}}(w, z) \equiv(1+\rho z) c$, where $\rho>0$ is a parameter to be determined at the calibration stage. More specifically, we normalise $z \in[0,1]$ (without loss of generality, because units are arbitrary) so that we can interpret $z$ as the fraction of land that is allocated to organic production. Given this, before the advent of GM products the marginal costs of production are written as $\mathrm{MC}_{\mathrm{n}}=c+\alpha_{\mathrm{n}} \pi$ and $\mathrm{MC}_{\mathrm{b}}=(1+\rho z) c+\alpha_{b} \pi$, respectively. 
Post-innovation, GM food production, $x_{\mathrm{g}}$, becomes feasible. Given the standard effects of first-generation GM agricultural products, we assume that the main attribute of GM crops is to provide higher production efficiency at the farm level. We model that by postulating that the GM technology cuts the cost of the bundle of market-supplied inputs, ${ }^{13}$ such that the unit cost of market-supplied inputs for GM crop production is $\gamma c$, where $0<\gamma<1$. But GM products also impose the need for IP, which we model by postulating a unit segregation cost $s_{\mathrm{n}}$ on the production of conventional food, and a unit segregation cost $s_{\mathrm{b}}$ on the production of organic food. ${ }^{14}$ The parameter $s_{\mathrm{b}}$ will also capture the policies of organic food classification vis-à-vis the presence of trace amounts of GM food. ${ }^{15}$ Furthermore, GM regulation may mandate an additional unit cost $t$ for the producers of GM food (i.e. the mandatory labelling and traceability requirements envisioned by the EU). Thus, the introduction of GM products affects the production costs of all three food products, and the post-innovation marginal production costs are represented by

$$
\begin{gathered}
\mathrm{MC}_{\mathrm{n}}=c+\alpha_{\mathrm{n}} \pi+s_{\mathrm{n}} \\
\mathrm{MC}_{\mathrm{b}}=(1+\rho z) c+\alpha_{\mathrm{b}} \pi+s_{\mathrm{b}} \\
\mathrm{MC}_{\mathrm{g}}=\gamma c+\alpha_{\mathrm{n}} \pi+t .
\end{gathered}
$$

\subsection{Equilibrium}

Based on the foregoing, and given a fixed amount of land $L$, the (partial) competitive equilibrium in the agricultural sector after the GM innovation (assuming that all three products are produced) can be written as:

$$
\begin{gathered}
p_{\mathrm{n}}^{*}=c+\alpha_{\mathrm{n}} \pi^{*}+s_{\mathrm{n}} \\
p_{\mathrm{b}}^{*}=\left(1+\rho z^{*}\right) c+\alpha_{\mathrm{b}} \pi^{*}+s_{\mathrm{b}} \\
p_{\mathrm{g}}^{*}=\gamma c+\alpha_{\mathrm{n}} \pi^{*}+t \\
D^{\mathrm{b}}\left(p_{\mathrm{b}}^{*}, p_{\mathrm{n}}^{*}, p_{\mathrm{g}}^{*}\right)=x_{b}^{*} \\
D^{\mathrm{n}}\left(p_{\mathrm{b}}^{*}, p_{\mathrm{n}}^{*}, p_{\mathrm{g}}^{*}\right)=x_{n}^{*}
\end{gathered}
$$

\footnotetext{
${ }^{13}$ Note that this formulation is quite consistent with the existence of market power in the pricing of GM seeds, as in existing related models (e.g. Moschini and Lapan, 1997; Fulton and Giannakas, 2004; Lapan and Moschini, 2004), as long as innovators do not extract the entire efficiency gain, i.e. there is some spillover to farmers of the gross benefits (as found by Moschini et al., 2000 and Falck-Zepeda et al., 2000). In other words, cost reduction represented by the parameter $\gamma$ is to be interpreted as capturing the underlying efficiency gain in production, resulting from the innovation, which is the net of the possibly non-competitive pricing of the improved inputs. But for the rest of the marketing sector we postulate a competitive setting.

${ }^{14} \mathrm{~A}$ constant unit segregation cost is a simplification that is invoked to keep the solution tractable. More realistically, as pointed out by a reviewer, one could postulate variable unit segregation costs that reflect the existence of fixed costs in the segregation process, as well as the possibility of decreasing returns to scale (on some domain) because of congestion in the marketing channels.

${ }^{15}$ For example, the fact that the EU organic food classification envisions zero tolerance of GM product (as is also the case in the United States) can be interpreted as increasing the value of $s_{\mathrm{b}}$.

(C) Blackwell Publishing Ltd. 2005
} 


$$
\begin{gathered}
D^{\mathrm{g}}\left(p_{\mathrm{b}}^{*}, p_{\mathrm{n}}^{*}, p_{\mathrm{g}}^{*}\right)=x_{\mathrm{g}}^{*} \\
z^{*} L=\alpha_{\mathrm{b}} x_{\mathrm{b}}^{*} \\
L=\alpha_{\mathrm{b}} x_{\mathrm{b}}^{*}+\alpha_{\mathrm{n}} x_{\mathrm{n}}^{*}+\alpha_{\mathrm{n}} x_{\mathrm{g}}^{*} .
\end{gathered}
$$

Equations (21)-(23) represent the competitive production conditions (marginal cost equals price) for the three outputs of the sector, where marginal costs account for the (endogenous) rent on land and the existence of segregation costs. Equations (24)-(26) represent clearing conditions (equality between demand and supply) in the three food markets. Equation (28) accounts for equilibrium in the land market (demand for land from the three industries equals the exogenously given land endowment) and equation (27) ensures the feasibility of the equilibrium level of organic production. The eight equilibrium conditions (21)-(28) yield the post-innovation equilibrium values of the eight endogenous variables $\left(x_{\mathrm{b}}^{*}, x_{\mathrm{n}}^{*}, x_{\mathrm{g}}^{*}, p_{\mathrm{b}}^{*}, p_{\mathrm{n}}^{*}, p_{\mathrm{g}}^{*}, z^{*}, \pi^{*}\right)$. The pre-innovation equilibrium is a special case, obtained by dropping equations (23) and (26), by setting $s_{\mathrm{n}}=s_{\mathrm{b}}=t=0$, and by constraining the price of the new product to $\bar{p}_{\mathrm{g}}$ (the choke price, i.e. the price that would drive GM food demand to zero). The resulting conditions can then be solved for the pre-innovation equilibrium values $\left(x_{\mathrm{b}}^{*}, x_{\mathrm{n}}^{*}, p_{\mathrm{b}}^{*}, p_{\mathrm{n}}^{*}, z^{*}, \pi^{*}\right){ }^{16}$

\section{Data and Calibration}

We present the data on the parameters of the model in Table 1, which refer to the year 2000. Data for the total EU UAA are obtained from the EU Directorate General for Agriculture (2003). The land utilised by the quality products (mostly represented by organic food), which is denoted by $L_{\mathrm{b}}$, amounts to $2.9 \%$ of the total EU UAA (Hamm et al., 2002). The rest of the total EU UAA is assumed to be allocated to normal food production, which is denoted by $L_{\mathrm{n}}$. The value of total agricultural production is obtained from the report of the EU Directorate General for Agriculture (2003). The value of organic food production is calculated based on data reported by Hamm et al. (2002). The difference between the values of total and the organic food production is accounted as the value of conventional food production. The price of conventional food is normalised to 1 , so that the amount of conventional food production is the value of conventional food production. The yield for the conventional product is then calculated by dividing the estimated production in volume by the estimated land used for the conventional product.

The price index for organic products that we have computed displays the price premium of such products over the conventional ones (the price of which was normalised to 1). Using this premium, the amount of organic food production is obtained by dividing the value of organic food with its price index. The yield for organic food production is calculated by dividing the amount of organic food production by the amount of land used in that industry. Using the data on average rent per hectare and the amount of agricultural land for each country in the EU

\footnotetext{
${ }^{16}$ Again, note that we are assuming competitive conditions, apart from the possible market power in the pricing of GM seeds that is implicit in our model (as noted in footnote 12). A reviewer suggested that possible market power in the food and retail industries should also be considered. But given the focus of this paper, such an undertaking is best left for future research.
} 
Table 1

Parameters implemented in the baseline

\begin{tabular}{lllc}
\hline & \multicolumn{1}{c}{ Description } & Unit & Values \\
\hline $\begin{array}{lll}\text { Primary data } \\
V_{\mathrm{T}}\end{array}$ & Total value of production & $b €$ & 248.5 \\
$V_{\mathrm{b}}$ & Value of organic food production & $b €$ & 2.79 \\
$L$ & Total UAA in the EU & $m h a$ & 130.3 \\
$L_{\mathrm{b}}$ & Land allocated to organic food & $m h a$ & 3.78 \\
$\pi$ & Unit land rent & $€ / h a$ & 208.8 \\
Calculated & & & \\
$p_{\mathrm{n}}$ & Price of normal food (price index) & $€ / u$ & 1.00 \\
$p_{\mathrm{b}}$ & Price of organic food (price index) & $€ / u$ & 1.63 \\
$V_{\mathrm{n}}=V_{\mathrm{T}}-V_{\mathrm{b}}$ & Value of normal food production & $b €$ & 245.7 \\
$x_{\mathrm{n}}=V_{\mathrm{n}}$ & Normal food production & $b u$ & 245.7 \\
$L_{\mathrm{n}}=L-L_{\mathrm{b}}$ & Land allocated to normal food & $m h a$ & 126.6 \\
$\alpha_{\mathrm{n}}=L_{\mathrm{n}} / x_{\mathrm{n}}$ & Reciprocal of yield, normal food & $u / h a$ & 1941 \\
$x_{\mathrm{b}}=V_{\mathrm{b}} / p_{\mathrm{b}}$ & Organic food production & $b u$ & 1.71 \\
$\alpha_{\mathrm{b}}=L_{\mathrm{b}} / x_{\mathrm{b}}$ & Reciprocal of yield, organic food & $u / h a$ & 452 \\
$c=p_{\mathrm{n}}-\alpha_{\mathrm{n}} \pi$ & Unit cost of market input bundle & $€ / u$ & 0.89 \\
$z=L_{\mathrm{b}} / L$ & Fraction of land allocated to organic & & 0.029 \\
Assumed and calibrated & & & \\
$s_{\mathrm{n}}$ & Segregation cost for normal food & $€ / u$ & 0.05 \\
$s_{\mathrm{b}}$ & Segregation cost for organic food & $€ / u$ & 0.05 \\
$\gamma$ & GM product efficiency parameter & & 0.98 \\
$t$ & Unit labelling and traceability cost & $€ / u$ & 0 \\
$\phi$ & Share of indifferent consumers & & 0.25 \\
$\varepsilon$ & Total demand elasticity & & 0.40 \\
$\rho$ & Organic production parameter & & 10.65 \\
\hline
\end{tabular}

Note: $€=$ euros, $b=$ billion, $h a=$ hectare, $m=$ million, $u=$ unit of production (index number).

(EU Directorate General for Agriculture, 2003), the rent attributable to total utilised land was calculated to be $11 \%$ of the total value of agriculture in the EU. The value of $\pi$ (unit rent) is then obtained by dividing total rent by the total amount of land. Then, the average production cost for conventional food $(c)$ was calculated as the difference between the price of conventional food and rent expense per unit of conventional food, as formulated in equation (21) (with $s_{\mathrm{n}}=0$ ).

The economics of IP and segregation for different commodities and markets have been studied in recent years (Buckwell et al., 1999), and some preliminary estimates of likely segregation costs are available. In particular, the study by the European Commission (2002) analysing possible co-existence scenarios suggests IP costs in the ranges of $4.5-9.5 \%$ for maize and $1.4-3.2 \%$ for potatoes (to meet a $1 \%$ threshold level). Desquilbet and Bullock (2001) considered the segregation costs at the farm and handling stages to be $4 \%$ of the farm price and $20 \%$ of the handler's markup at maximum. Sobolevsky et al. (2005) rely on Lin et al. (2000) and use segregation costs between $3.4 \%$ and $10.3 \%$ of the average US producers' price for soyabean. Based on the foregoing, in this study, we took the segregation cost to be $5 \%$ of the selling price in the baseline solution. Therefore, because the pre-innovation price of conventional 
food is normalised to equal 1 , the unit segregation costs $s_{\mathrm{n}}$ and $s_{\mathrm{b}}$ for conventional and organic products, respectively, are set to $0.05 €$ in the baseline scenario.

There seems to be widespread agreement that GM crops can provide substantial efficiency gains relative to their conventional counterparts, although there is less agreement on the magnitude of such gains (e.g. Moschini et al. 2000; Bullock and Nitsi, 2001; Marra et al., 2002; Qaim and Zilberman, 2003; Qaim and Traxler, 2005). To be broadly consistent with such studies, here we (perhaps conservatively) assume that the introduction of GM technology yields a $2 \%$ reduction in average cost of GM food production. But note that, as discussed in footnote 12, this figure is to be interpreted as representing the farm-level cost saving net of the price markup typically associated with GM seeds (as implied by the market power caused by the proprietary nature of GM technology). Thus, in our baseline model, we put $\gamma=0.98$.

Labelling and traceability costs are implemented in the model by the parameter $t$. In the baseline solution we assume $t=0$, but consider alternatives at the sensitivity analysis stage. Finally, the parameter representing the percentage of consumers who are indifferent between GM and conventional food versions (when the two varieties are offered at the same price) is taken to be $\phi=0.25$ based on the survey results (Moon and Balasubramanian, 2001) and experimental findings (Noussair et al., 2004). As noted earlier, without loss of generality, we assume that those indifferent consumers will purchase GM food (any other allocation of indifferent consumers could be implemented by changing the value of $\phi$ ).

Given the above, what remains is to calibrate the demand parameters $(\varepsilon>0, \kappa>0$ and $\lambda>0)$ and the production parameter $\rho>0$. We do so by ensuring that, given the other assumptions detailed in the foregoing, the chosen parameters allow the model to replicate the observed prices and quantities for the benchmark year 2000 . Specifically, in the pre-innovation competitive equilibrium $\left(s_{\mathrm{b}}=0\right)$, by using the data presented in Table 1 and given the unit rent $\pi=208.8$ computed as described earlier from equation (21) (with $s_{n}=0$ ), the production cost parameter $c$ must satisfy $\left(p_{n}-c\right) / \alpha_{n}=208.8$. Next, given $\pi=208.8$ and $z=0.029$ (obtained as the fraction of land allocated to organic production), from equation (22) of the pre-innovation equilibrium, we solve for $\rho=10.653$.

To calibrate the demand parameters involves making assumptions about the parameters $(\kappa, \varepsilon, \lambda)$ such that the benchmark prices and quantities are replicated, in addition to satisfying probable values of the demand elasticities involved. A possible difficulty in this context is that the parameters govern not only the own-price elasticities but also the cross-price elasticities (including elasticities of demand for GM food, a product that was not yet on the market in the benchmark year). But our specification is particularly useful here, because we can deduce the behaviour of the demand system from the value of total elasticity that refers to aggregate food demand. To see this, define total demand as:

$$
D^{\mathrm{T}}\left(p_{\mathrm{b}}, p_{\mathrm{n}}, p_{\mathrm{g}}\right) \equiv D^{\mathrm{b}}\left(p_{\mathrm{b}}, p_{\mathrm{n}}, p_{\mathrm{g}}\right)+D^{\mathrm{n}}\left(p_{\mathrm{b}}, p_{\mathrm{n}}, p_{\mathrm{g}}\right)+D^{\mathrm{g}}\left(p_{\mathrm{b}}, p_{\mathrm{n}}, p_{\mathrm{g}}\right) .
$$

Given this, we define total demand elasticity as:

$$
\eta_{\mathrm{T}}=\left.\frac{\partial D^{\mathrm{T}}\left(\tau p_{\mathrm{b}}, \tau p_{\mathrm{n}}, \tau p_{\mathrm{g}}\right)}{\partial \tau} \frac{\tau}{D^{\mathrm{T}}\left(\tau p_{\mathrm{b}}, \tau p_{\mathrm{n}}, \tau p_{\mathrm{g}}\right)}\right|_{\tau=1} .
$$

It can be verified that, in our demand structure, we have $\eta_{T}=-\varepsilon$. Thus, the parameter $\varepsilon$ is a measure of the elasticity of total food demand, which is known to be quite 
inelastic in developed countries (Gracia et al., 1998; Moschini, 1998; Tiffin and Tiffin, 1999). But here we also need to consider that in our model the demand is for EU-produced food (i.e. net of import and exports), and thus it is probably more elastic than the final EU demand for food. Given this likelihood, in the baseline solution, we assume $\varepsilon=0.4$. Conditional on these elasticity values, the market-clearing conditions in equations (24)-(25) (with the price of GM product set to the choke level $\bar{p}_{g}$ ) are solved for the remaining two demand parameters, by using the demand functions from equations (14) and (15), to yield $k=238.7$ (billion) and $\lambda=0.989$.

\section{Results}

Given our calibration procedure, solving the model for the pre-innovation equilibrium replicates observed price and quantity levels for the year 2000. Solving the model for the post-innovation equilibrium allows us to trace the main economic implications of the adoption of GM products. The economic effects that we focus on relate to the direction of price changes for traditional, organic and GM products and the distribution of welfare effects across agents (consumers and producers). Specifically, in our model, there are three welfare effects of interest. First, consumers are affected by the innovation, and thus we wish to compute the change in aggregate consumer surplus, $\Delta \mathrm{CS}$. Agricultural producers' welfare is also affected by the innovation. In particular, our model admits two distinct components of what is usually referred to as producer surplus change, $\triangle \mathrm{PS}$ : a change in the return to land and a change in the return to efforts for producers of organic product.

Consider first consumer welfare. Denote the pre- and post-innovation equilibrium solutions with superscripts $i=0$ and $i=1$, respectively, such that the pre- and post-equilibrium prices are written as $\left(p_{\mathrm{n}}^{0}, p_{\mathrm{b}}^{0}, p_{\mathrm{g}}^{0}\right)$ and $\left(p_{\mathrm{n}}^{1}, p_{\mathrm{b}}^{1}, p_{\mathrm{g}}^{1}\right)$. It follows that the change in total consumer surplus is

$$
\Delta \mathrm{CS}=-\int_{p_{\mathrm{b}}^{0}}^{p_{\mathrm{b}}^{1}} D_{\mathrm{b}}\left(p_{\mathrm{b}}, p_{\mathrm{n}}^{0}, p_{\mathrm{g}}^{0}\right) \mathrm{d} p_{\mathrm{b}}-\int_{p_{\mathrm{n}}^{0}}^{p_{\mathrm{n}}^{1}} D_{\mathrm{n}}\left(p_{\mathrm{b}}^{1}, p_{\mathrm{n}}, p_{\mathrm{g}}^{0}\right) \mathrm{d} p_{\mathrm{n}}-\int_{p_{\mathrm{g}}^{0}}^{p_{\mathrm{g}}^{1}} D_{\mathrm{g}}\left(p_{\mathrm{b}}^{1} ; p_{\mathrm{n}}^{1}, p_{\mathrm{g}}\right) \mathrm{d} p_{\mathrm{g}} .
$$

As for producer surplus, as mentioned earlier, our model admits two distinct components. Consider the return to efforts for organic food producers, labelled as $R_{\mathrm{b}}^{i}$, $i \in\{0,1\}$. Then, in our model, these returns satisfy

$$
\begin{aligned}
R_{\mathrm{b}}^{i} & \equiv \frac{L}{\alpha_{\mathrm{b}}} \int_{0}^{z^{i}}\left[p_{\mathrm{b}}^{i}-\mathrm{MC}_{\mathrm{b}}^{i}(z)\right] \mathrm{d} z \\
& =\frac{\left(z^{i}\right)^{2} L \rho c}{2 \alpha_{\mathrm{b}}}
\end{aligned}
$$

where $\operatorname{MC}_{\mathrm{b}}^{i}(z)=\left(1+\rho z^{i}\right) c+\alpha_{\mathrm{b}} \pi^{i}+s_{\mathrm{b}}^{i}$. The other component of producer surplus is the return to landowners at equilibria $i \in\{0,1\}$, which satisfies $V_{L}^{i}=\pi^{i} L$. Hence, the change in surplus accruing to landowners is $\Delta V_{L}=\left(\pi^{1}-\pi^{0}\right) L$ and the change in surplus accruing to organic food producers is $\Delta R_{\mathrm{b}}=R_{\mathrm{b}}^{1}-R_{\mathrm{b}}^{0}$, such that the total change in producer surplus is $\Delta \mathrm{PS}=\Delta R_{\mathrm{b}}+\Delta V_{L}$. Finally, total welfare change arising from the innovation is measured as $\Delta W=\Delta \mathrm{CS}+\Delta \mathrm{PS}$.

\subsection{Baseline scenario}

In the base scenario, the model was solved with the calibrated parameters reported in Table 1. Note that the cost for labelling and traceability of GM food (over and 
above the cost of IP) here is set equal to zero (i.e. $t=0$ ). Although minimal costs are probably involved in labelling GM food per se, the record-keeping mandated by the traceability requirements on GM food is probably more onerous. Still, as the benchmark of zero labelling and traceability costs is of some interest, especially if one wants to disentangle the effects of such activities from the actual segregation costs necessary to supply consumers with what they perceive as the superior products (conventional and organic food with IP), we begin our analysis with that assumption. We perform sensitivity analysis regarding this parameter value later. The other critical parameter is the segregation cost. In the baseline scenario, we assume that conventional food and organic food face the same segregation costs, following the introduction of GM products, and thus (as per earlier discussion) we set $s_{\mathrm{n}}=s_{\mathrm{b}}=0.05$.

Results for the base scenario are reported in Table 2. With the introduction of GM food, the price of GM food declines relative to the pre-innovation choke price (recall that there is no demand for GM food for all $p_{\mathrm{g}}>p_{\mathrm{n}}$ ), and this new product displaces mainly the conventional product (the production of which decreases by $30.7 \%$ ). To interpret these and subsequent results, it helps to note explicitly that the difference in equilibrium prices between conventional and GM products is determined by the supply side of the model, specifically $p_{\mathrm{n}}^{*}-p_{\mathrm{g}}^{*}=(1-\gamma) c+s_{\mathrm{n}}-t$. Given this price difference, in turn, the demand side determines the relative share of GM and non-GM products on the market. In the absence of segregation costs, the introduction of a more efficient production (the GM product) would tend to

Table 2

Baseline scenario results

\begin{tabular}{|c|c|c|c|c|c|}
\hline \multirow[b]{2}{*}{ Variable } & \multirow[b]{2}{*}{ Unit } & \multicolumn{2}{|c|}{ Values } & \multicolumn{2}{|c|}{ Variation } \\
\hline & & Pre-innovation & Post-innovation & Level & $\%$ \\
\hline \multicolumn{6}{|l|}{ Demand prices } \\
\hline Normal food $\left(p_{\mathrm{n}}\right)$ & $€ / u$ & 1.00 & 1.026 & 0.026 & 2.55 \\
\hline Organic food $\left(p_{\mathrm{b}}\right)$ & $€ / u$ & 1.63 & 1.584 & -0.046 & -2.83 \\
\hline GM food $\left(p_{\mathrm{g}}\right)$ & $€ / u$ & $>1.00$ & 0.958 & -0.055 & -5.44 \\
\hline \multicolumn{6}{|l|}{ Producer prices } \\
\hline Normal food $\left(p_{\mathrm{n}}-s_{\mathrm{n}}\right)$ & $€ / u$ & 1.00 & 0.976 & -0.024 & -2.45 \\
\hline Organic food $\left(p_{\mathrm{b}}-s_{\mathrm{b}}\right)$ & $€ / u$ & 1.63 & 1.534 & -0.096 & -5.90 \\
\hline $\mathrm{GM}$ food $\left(p_{\mathrm{g}}-t\right)$ & $€ / u$ & $>1.00$ & 0.958 & -0.055 & -5.44 \\
\hline \multicolumn{6}{|l|}{ Food production } \\
\hline Normal food $\left(x_{\mathrm{n}}\right)$ & $b u$ & 245.71 & 170.31 & -75.41 & -30.69 \\
\hline Organic food $\left(x_{\mathrm{b}}\right)$ & $b u$ & 1.71 & 1.77 & 0.06 & 3.30 \\
\hline GM food $\left(x_{\mathrm{g}}\right)$ & $b u$ & 0.00 & 75.17 & 75.17 & - \\
\hline Total segregation costs & $b €$ & 0.00 & 8.60 & 8.60 & - \\
\hline Unit land rent $(\pi)$ & $€ / h a$ & 208.79 & 161.24 & -47.55 & -22.78 \\
\hline Total return to land & $b €$ & 27.21 & 21.02 & -6.20 & -22.78 \\
\hline Profit of organic producers & $m €$ & 235.57 & 251.35 & 15.78 & 6.70 \\
\hline Producer surplus & $b €$ & 27.45 & 21.27 & -6.18 & -22.52 \\
\hline Consumer surplus & $b €$ & - & - & -1.55 & - \\
\hline Aggregate welfare & $b €$ & - & - & -7.73 & - \\
\hline
\end{tabular}

Note: See Table 1 for the definition of units of measurement. 
increase the returns to land (the unit rent $\pi$ ). But the existence of segregation costs puts a wedge between the demand prices and supply prices for the conventional and organic products and leads to a sizeable erosion to the returns to land (the fixed factor). At the demand level, the price of GM food of course decreases relative to the pre-innovation choke price level. The price of organic food decreases at the demand level (despite the need for segregation) because the production-cost impact of the decline in the rental price of land is more important for this (land-extensive) sector. The price of conventional food, on the contrary, increases at the demand level (because the effect of segregation costs, which acts like a tax, dominates).

All producer prices decrease in the new equilibrium (which, in turn, accounts for the decrease in unit rent value of land). As for welfare effects, returns to land of course decline, but the non-land returns to organic food producers increase. Overall, however, the returns to land obviously dominate, and producer surplus declines substantially. Consumer surplus also declines: given our parameterised preferences, the decline in the price of GM and organic food is not enough to compensate for the increase in conventional food price. Because both producers and consumers lose in the aggregate, the introduction of GM food in the EU agro-food system unambiguously decreases the total welfare by 7.7 billion euros. We should emphasise again that, unlike other studies in this area, in our calculation we do not account for the ex post returns to innovators who develop the GM crops. ${ }^{17}$

To further illustrate and qualify the foregoing results of the baseline scenarios, in what follows we carry out a sensitivity analysis, whereby the effects of changes in the value of some key parameters are explored. ${ }^{18}$

\subsection{Effects of segregation costs for organic food}

In the baseline solution we postulated that segregation costs for conventional and organic food are equal, that is, $s_{\mathrm{n}}=s_{\mathrm{b}}$. But it is of interest to analyse the effects of two alternative polar situations. The first situation is the case that $s_{\mathrm{b}}<s_{\mathrm{n}}$. A justification for this scenario derives from the observation that organic products derive from well-specified production practices that inherently already include elements of identity preservation. Thus, one can hypothesise that there may be a smaller segregation cost for organic products, relative to conventional products, following the introduction of GM food. But the alternative of $s_{\mathrm{b}}>s_{\mathrm{n}}$ is also quite relevant, because organic production insists on a zero-tolerance level for the adventitious presence of GM material. Meeting this stricter standard is, of course, bound to be costlier.

The results concerning the impact of segregation costs are reported in Table 3 . The first column, in particular, computes the impact of the innovation if in fact all such costs were absent. This (unrealistic) scenario is useful as a benchmark. Note, in particular, that both producers and consumers overall would benefit

\footnotetext{
${ }^{17}$ One way to rationalise our procedure is to consider ex post returns to innovators as compensating, in expectation, for the $R \& D$ investments that made the innovation possible.

${ }^{18}$ In addition to what is reported in Tables 3 to 5 , we also performed sensitivity analysis on the value of the demand elasticity $\varepsilon$. Although omitted here for space reasons, we can note that such sensitivity analysis results remain qualitatively similar to those of the baseline scenario.
} 
Table 3

Sensitivity analysis on segregation costs

\begin{tabular}{|c|c|c|c|c|c|c|}
\hline \multirow[b]{2}{*}{ Variable } & \multicolumn{6}{|c|}{ Segregation costs } \\
\hline & $\begin{array}{l}s_{\mathrm{b}}=0 \\
s_{\mathrm{n}}=0\end{array}$ & $\begin{array}{l}s_{\mathrm{b}}=B \\
s_{\mathrm{n}}=B\end{array}$ & $\begin{array}{c}s_{\mathrm{b}}=B / 2 \\
s_{\mathrm{n}}=B\end{array}$ & $\begin{array}{c}s_{b}=2 B \\
s_{\mathrm{n}}=B\end{array}$ & $\begin{array}{l}s_{\mathrm{b}}=B / 2 \\
s_{\mathrm{n}}=B / 2\end{array}$ & $\begin{array}{l}s_{\mathrm{b}}=2 B \\
s_{n}=2 B\end{array}$ \\
\hline \multicolumn{7}{|l|}{ Consumer prices } \\
\hline Normal food $\left(p_{\mathrm{n}}\right)$ & 1.0044 & 1.0255 & 1.0262 & 1.0241 & 1.0141 & 1.0530 \\
\hline Organic food $\left(p_{\mathrm{b}}\right)$ & 1.6460 & 1.5839 & 1.5655 & 1.6211 & 1.6117 & 1.5463 \\
\hline GM food $\left(p_{\mathrm{g}}\right)$ & 0.9865 & 0.9577 & 0.9584 & 0.9563 & 0.9713 & 0.9352 \\
\hline \multicolumn{7}{|l|}{ Producer prices } \\
\hline Normal $\left(p_{\mathrm{n}}-s_{\mathrm{n}}\right)$ & 1.0044 & 0.9755 & 0.9762 & 0.9741 & 0.9891 & 0.9530 \\
\hline Organic $\left(p_{\mathrm{b}}-s_{\mathrm{b}}\right)$ & 1.6460 & 1.5339 & 1.5405 & 1.5211 & 1.5867 & 1.4463 \\
\hline $\mathrm{GM}$ food $\left(p_{\mathrm{g}}-t\right)$ & 0.9865 & 0.9577 & 0.9584 & 0.9563 & 0.9713 & 0.9352 \\
\hline \multicolumn{7}{|l|}{ Food production } \\
\hline Normal food $\left(x_{\mathrm{n}}\right)$ & 180.70 & 170.31 & 170.25 & 170.41 & 175.48 & 160.20 \\
\hline Organic food $\left(x_{\mathrm{b}}\right)$ & 1.69 & 1.77 & 1.79 & 1.72 & 1.73 & 1.82 \\
\hline GM food $\left(x_{\mathrm{g}}\right)$ & 65.08 & 75.17 & 75.13 & 75.24 & 70.14 & 85.04 \\
\hline Segregation costs & 0.00 & 8.60 & 8.56 & 8.69 & 4.43 & 16.20 \\
\hline Unit land rent $(\pi)$ & 217.26 & 161.24 & 162.65 & 158.52 & 187.64 & 117.64 \\
\hline Total return to land & 28.32 & 21.02 & 21.20 & 20.66 & 24.46 & 15.33 \\
\hline Profit of organic producers & 230.97 & 251.35 & 257.48 & 239.61 & 241.65 & 267.15 \\
\hline Producer surplus & 28.55 & 21.27 & 21.46 & 20.90 & 24.70 & 15.60 \\
\hline Variation in consumer surplus & 0.03 & -1.55 & -1.69 & -1.27 & -0.61 & -4.23 \\
\hline Variation in aggregate welfare & 1.13 & -7.73 & -7.69 & -7.82 & -3.37 & -16.08 \\
\hline
\end{tabular}

Note: $B=$ base value (see Table 1). See Table 1 for the units of measurement and Table 2 for the pre-innovation solution.

from the GM innovation, and so aggregate welfare increases. But the returns to organic producers would decrease in such a scenario because of the double impact of competition at the demand level (one more substitute product is available) and because of the increase in the returns to land (which causes production costs to increase for the organic industry proportionally more than in the other industries).

To ascertain the potential impact of alternative scenarios for the cost of segregating organic food, the parameter $s_{\mathrm{b}}$ is halved and doubled whereas all other parameters are kept at their baseline values. The results reported in Table 3 show that a lower segregation cost for organic food leads to a lower equilibrium price for organic food, as expected, whereas the equilibrium prices of other goods increase. The effect on the equilibrium quantity demanded is for organic food to increase (relative to the benchmark) and for the other two products to decrease, although the magnitude of these effects is somewhat small. Per-hectare rent remains higher than at the baseline, which increases the cost of production so that prices for conventional and GM food are higher compared with the baseline.

Both components of producer surplus increase relative to the baseline, whereas consumer surplus is actually lower than at the baseline (the additional decrease in organic food price does not offset the small price increases in the other two 
products). Overall, aggregate welfare is minimally improved (relative to the baseline). Doubling $s_{\mathrm{b}}$ has essentially the opposite effect of halving it, and therefore the economic effects are qualitatively reversed relative to the baseline.

\subsection{Effects of the overall level of segregation costs}

As discussed earlier, a wide range of segregation costs have been contemplated in previous studies, and much uncertainty remains as to their actual level because large-scale segregation of GM and non-GM products has not yet been attempted. The parameter value for segregation costs used in the baseline reflects an average of values found in previous studies, but clearly it is of interest to evaluate the model's sensitivity to changes in the level of segregation cost. To that end, here we maintain the baseline assumption that segregation costs for organic and conventional products are the same $\left(s_{\mathrm{n}}=s_{\mathrm{b}}\right)$, and consider the effects of doubling and halving their level. The results are reported in the last two columns of Table 3.

None of the results qualitatively change relative to the pre-innovation scenario. For higher segregation costs, the equilibrium producers' prices are uniformly lower than at the baseline; at the demand level, the only price that increases (relative to the baseline) is that of conventional food (the largest industry here). The production of organic food and of GM food both expand, whereas the production of conventional food decreases relative to the baseline. The gain to consumers because of the decrease in the prices of GM and organic food does not outweigh their losses caused by the increase in the price of conventional food, and consumers are (as expected) negatively impacted by the larger segregation costs. Organic food producers' returns increase, as does their supply, but overall the higher segregation costs hurt producers, consumers and aggregate welfare. Halving the segregation costs works just the opposite of doubling them, so the results are qualitatively reversed relative to the baseline case. In particular, both GM and organic food production decrease (relative to the baseline). Overall welfare is improved but organic producers actually prefer uniformly higher segregation costs.

\subsection{Effects of GM labelling and traceability costs}

Labelling and traceability of GM food envisioned by the current EU regulation, as discussed earlier, clearly increases the costs of marketing GM products whereas it arguably does not affect the IP costs of non-GM products (which still have to undertake all the many IP activities that are required to ensure segregation at the desired purity level). In the baseline, we set the labelling and traceability costs to zero in order to disentangle their effects from those of segregation costs, which are necessary to preserve the identity of conventional and organic food. We now perform a sensitivity analysis by allowing this parameter to take positive values, specifically one fourth and one half of the segregation cost for conventional food (set at the baseline value). The results are presented in Table 4.

The positive labelling and traceability costs, over and above segregation costs, have a direct negative impact on the supply price of GM food, which in turn tends to decrease the returns to land. The latter affects the unit production costs so that, in equilibrium, the demand prices of conventional and organic food are also lower 
Table 4

Sensitivity analysis on labelling and traceability costs

\begin{tabular}{|c|c|c|c|}
\hline \multirow[b]{2}{*}{ Variable } & \multirow[b]{2}{*}{ Baseline $(t=0)$} & \multicolumn{2}{|c|}{$\begin{array}{l}\text { Labelling and traceability } \\
\text { costs }\end{array}$} \\
\hline & & $t=s_{\mathrm{n}} / 4$ & $t=s_{\mathrm{n}} / 2$ \\
\hline \multicolumn{4}{|l|}{ Consumer prices } \\
\hline Normal food $\left(p_{\mathrm{n}}\right)$ & 1.0255 & 1.0208 & 1.0165 \\
\hline Organic food $\left(p_{\mathrm{b}}\right)$ & 1.5839 & 1.5666 & 1.5509 \\
\hline GM food $\left(p_{\mathrm{g}}\right)$ & 0.9577 & 0.9654 & 0.9736 \\
\hline \multicolumn{4}{|l|}{ Producer prices } \\
\hline Normal food $\left(p_{\mathrm{n}}-s_{\mathrm{n}}\right)$ & 0.9755 & 0.9708 & 0.9665 \\
\hline Organic food $\left(p_{\mathrm{b}}-s_{\mathrm{b}}\right)$ & 1.5339 & 1.5166 & 1.5009 \\
\hline $\mathrm{GM}$ food $\left(p_{\mathrm{g}}-t\right)$ & 0.9577 & 0.9529 & 0.9486 \\
\hline \multicolumn{4}{|l|}{ Food production } \\
\hline Normal food $\left(x_{n}\right)$ & 170.31 & 172.80 & 175.29 \\
\hline Organic food $\left(x_{\mathrm{b}}\right)$ & 1.77 & 1.78 & 1.80 \\
\hline GM food $\left(x_{\mathrm{g}}\right)$ & 75.17 & 72.60 & 70.03 \\
\hline Segregation and labelling costs & 8.60 & 9.64 & 10.61 \\
\hline Unit land rent $(\pi)$ & 161.24 & 152.07 & 143.71 \\
\hline Total return to land & 21.02 & 19.82 & 18.73 \\
\hline Profit of organic producers & 251.35 & 256.61 & 261.59 \\
\hline Producer surplus & 21.27 & 20.08 & 18.99 \\
\hline Variation in consumers surplus & -1.55 & -1.28 & -1.09 \\
\hline Variation in aggregate welfare & -7.73 & -8.66 & -9.55 \\
\hline
\end{tabular}

Note: See Table 1 for units of measurement and Table 2 for the pre-innovation solution. Parameter $s_{\mathrm{n}}$ set at baseline value of 0.05 .

(but the price of GM food is higher because of the tax-like effect of the GM labelling and traceability requirements). The returns to producers of quality food are improved by labelling and traceability costs imposed on GM producers, compared with the baseline. But the organic industry is small, and for the overall producer surplus the further drop in the returns to land tends to dominate. Consumer surplus is actually improved by positive labelling and traceability costs, because consumers can enjoy the lower equilibrium prices of conventional and organic products. Overall aggregate welfare, however, is negatively impacted (producers lose more than consumers gain).

\subsection{Effects of the size of GM innovation}

The parameter for cost reduction due to GM technology indexes the farmers' net benefit from adopting GM innovation. The value $\gamma=0.98$ used in the baseline is an educated guess based on the values suggested in the literature. Our sensitivity analysis of this parameter considered $\gamma=0.99$ and $\gamma=0.97$. The results (not reported here but available upon request) show that the size of the GM innovation does not change the qualitative insights obtained in the baseline. For a lower value of the parameter $\gamma$, the cost reduction from GM innovation becomes higher and GM production slightly expands. The opposite is true for the higher value of the parameter $\gamma$. The qualitative effects on prices are 
intuitive. As for welfare, a larger GM innovation improves overall welfare and returns to land, relative to the baseline, but decreases consumer surplus and the returns to organic producers.

\subsection{Effects of the size of the population of indifferent consumers}

Our baseline parameter $\phi=0.25$ assumes that $25 \%$ of EU consumers are, essentially, indifferent to the GM nature of food produced from GM crops; as long as, in equilibrium, the new product commands a lower price (no matter how small the difference), these consumers would consume the new product. As discussed earlier, this parameterisation captures an important attribute of the demand impact of the introduction of the new, weakly inferior GM products. But how important is the actual size of the parameter $\phi$ for our conclusions? Table 5 provides some sensitivity analysis that considers various alternative values for this parameter.

When $\phi=1-$ a scenario in which all consumers are indifferent between GM and conventional food - the GM food completely supplants the pre-existing non-GM conventional food. This scenario would be associated with an increase in the returns to land (which captures most of the efficiency gains of the innovation), but consumers also gain and there is a sizeable overall welfare gain. The losers in such a setting

Table 5

Sensitivity analysis on the population of indifferent consumers

\begin{tabular}{|c|c|c|c|c|c|}
\hline \multirow[b]{2}{*}{ Variable } & \multirow{2}{*}{$\begin{array}{l}\text { Baseline } \\
(\phi=0.25)\end{array}$} & \multicolumn{4}{|c|}{$\begin{array}{c}\text { Size of population of indifferent } \\
\text { consumers }\end{array}$} \\
\hline & & $\phi=0.125$ & $\phi=0.5$ & $\phi=0.75$ & $\phi=1$ \\
\hline \multicolumn{6}{|l|}{ Consumer prices } \\
\hline Normal food $\left(p_{\mathrm{n}}\right)$ & 1.0255 & 1.0189 & 1.0387 & 1.0517 & 1.0646 \\
\hline Organic food $\left(p_{\mathrm{b}}\right)$ & 1.5839 & 1.5600 & 1.6316 & 1.6793 & 1.7268 \\
\hline GM food $\left(p_{\mathrm{g}}\right)$ & 0.9577 & 0.9510 & 0.9708 & 0.9838 & 0.9967 \\
\hline \multicolumn{6}{|l|}{ Producer prices } \\
\hline Normal food $\left(p_{\mathrm{n}}-s_{\mathrm{n}}\right)$ & 0.9755 & 0.9689 & 0.9887 & 1.0017 & 1.0146 \\
\hline Organic food $\left(p_{\mathrm{b}}-s_{\mathrm{b}}\right)$ & 1.5339 & 1.5100 & 1.5816 & 1.6293 & 1.6768 \\
\hline GM food $\left(p_{\mathrm{g}}-t\right)$ & 0.9577 & 0.9510 & 0.9708 & 0.9838 & 0.9967 \\
\hline \multicolumn{6}{|l|}{ Food production } \\
\hline Normal food $\left(x_{n}\right)$ & 170.31 & 199.10 & 113.07 & 56.31 & 0.00 \\
\hline Organic food $\left(x_{\mathrm{b}}\right)$ & 1.77 & 1.79 & 1.71 & 1.66 & 1.61 \\
\hline GM food $\left(x_{\mathrm{g}}\right)$ & 75.17 & 46.25 & 132.63 & 189.62 & 246.14 \\
\hline Total segregation costs & 8.60 & 10.04 & 5.74 & 2.90 & 0.08 \\
\hline Unit land rent $(\pi)$ & 161.24 & 148.36 & 186.79 & 212.08 & 237.12 \\
\hline Total returns to land & 21.02 & 19.34 & 24.35 & 27.64 & 30.91 \\
\hline Profit of organic producers & 251.35 & 259.54 & 236.05 & 222.06 & 209.25 \\
\hline Producer surplus & 21.27 & 19.60 & 24.58 & 27.86 & 31.11 \\
\hline Variation in consumer surplus & -1.55 & -1.90 & -0.83 & -0.10 & 0.64 \\
\hline Variation in aggregate welfare & -7.73 & -9.75 & -3.70 & 0.31 & 4.31 \\
\hline
\end{tabular}

Note: See Table 1 and Table 2 for the units of measurement, baseline values of parameters, and for the pre-innovation solution. 
would be the organic food producers, for three reasons: because the increased returns to land increase their production costs; because the competing product at the demand level is available at a slightly lower price; and because they still have to incur segregation costs to market their non-GM organic product to consumers. Decreasing the parameter $\phi$ (i.e. more and more consumers dislike the GM innovation) decreases overall welfare, returns to land and consumer surplus. But organic producers prefer a lower $\phi$ because that means that consumers are more attracted to their product (ceteris paribus) and because they can benefit from the reduced rental price of land.

\subsection{Some break-even points}

To sharpen the model's prediction on the potential quantitative impacts of GM product adoption on EU agriculture and welfare, the computation of 'break-even' points, which we report in Table 6, may be useful (Demont et al., 2004). Consider first the size of the innovation captured by the parameter $\gamma$. As is apparent, our model displays one of the insights formalised in Lapan and Moschini (2004): there is a possible market failure associated with the mere introduction of the new product which can have a negative impact on welfare. Indeed, our baseline solution indicates that overall welfare in the EU would drop as a result of GM

Table 6

Break-even analysis

\begin{tabular}{|c|c|c|c|c|}
\hline \multirow[b]{2}{*}{ Variable } & \multirow[b]{2}{*}{ Baseline } & \multicolumn{3}{|c|}{$\begin{array}{l}\text { Break-even value of given parameter } \\
\text { (all other parameters held at baseline value) }\end{array}$} \\
\hline & & $\gamma=0.8774$ & $s_{b}=s_{n}=0.0062$ & $\phi=0.7305$ \\
\hline \multicolumn{5}{|l|}{ Consumer prices } \\
\hline Normal food $\left(p_{\mathrm{n}}\right)$ & 1.0255 & 1.0723 & 1.0066 & 1.0507 \\
\hline Organic food $\left(p_{\mathrm{b}}\right)$ & 1.5839 & 1.7592 & 1.6369 & 1.6755 \\
\hline GM food $\left(p_{\mathrm{g}}\right)$ & 0.9577 & 0.9130 & 0.9826 & 0.9828 \\
\hline \multicolumn{5}{|l|}{ Producer prices } \\
\hline Normal food $\left(p_{\mathrm{n}}-s_{\mathrm{n}}\right)$ & 0.9755 & 1.0223 & 1.0004 & 1.0007 \\
\hline Organic food $\left(p_{\mathrm{b}}-s_{\mathrm{b}}\right)$ & 1.5339 & 1.7092 & 1.6307 & 1.6255 \\
\hline GM food $\left(p_{\mathrm{g}}-t\right)$ & 0.9577 & 0.9130 & 0.9826 & 0.9828 \\
\hline \multicolumn{5}{|l|}{ Food production } \\
\hline Normal food $\left(x_{n}\right)$ & 170.31 & 152.58 & 179.40 & 60.72 \\
\hline Organic food $\left(x_{\mathrm{b}}\right)$ & 1.77 & 1.60 & 1.70 & 1.66 \\
\hline GM food $\left(x_{\mathrm{g}}\right)$ & 75.17 & 93.58 & 66.34 & 185.19 \\
\hline Total segregation costs & 8.60 & 7.71 & 1.13 & 3.12 \\
\hline Unit land rent $(\pi)$ & 161.24 & 252.18 & 209.59 & 210.12 \\
\hline Total returns to land & 21.02 & 32.87 & 27.32 & 27.39 \\
\hline Profit of organic producers & 251.35 & 207.77 & 233.70 & 223.11 \\
\hline Producer surplus & 21.27 & 33.08 & 27.55 & 27.61 \\
\hline Variation in consumer surplus & -1.55 & -5.63 & -0.10 & -0.16 \\
\hline Variation in aggregate welfare & -7.73 & 0.00 & 0.00 & 0.00 \\
\hline
\end{tabular}

Note: See Table 1 and Table 2 for the units of measurement, baseline values of parameters, and for the pre-innovation solution. 
crop adoption, mostly because of the need for (hitherto unnecessary) segregation costs.

But, as the foregoing analysis indicates, the marginal impact of the innovation may be positive (because the externality effect is associated with the presence of the new GM activity, and not to its level, the possible market failure is essentially due to a non-convexity). So, is there a size of the innovation large enough to fully offset the aggregate negative welfare effects of the GM innovation? The answer is yes, in our model. But, as Table 6 indicates, the parameter $\gamma$ would have to be extraordinarily low: $\gamma=0.8774$; that is, GM crop production would need to entail an efficiency gain exceeding $12 \%$. Even at that, however, the break-even of aggregate welfare would be achieved at the expense of consumers and of organic food producers (both these groups would lose).

Next, we consider the impact of segregation costs. How low would they need to be, given our other baseline parameters, for aggregate welfare not to decrease? Very low indeed, in our model, as indicated in Table 6 . Specifically, we would need $s_{\mathrm{b}}=$ $s_{\mathrm{n}}=0.0062$; i.e. segregation costs would need to account for less than $1 \%$ of the supply price. Finally, for the break-even point of the parameter indexing the size of the population of indifferent consumers, we find $\phi=0.73$. This is much higher than our (conservative) baseline choice but perhaps not outside the set of likely values. The truth of the matter is that little is known about the quantitative attributes of consumer response to GM attributes in food. Our analysis here again emphasises the crucial importance that such preferences have on the calculation of possible market and welfare effects.

\section{Conclusion}

We have developed a partial equilibrium, multi-market model of the European agricultural sector, in which conventional food and organic food both exist prior to the introduction of GM products and may be differentially affected by this innovation. Although the model is rather stylised, it possesses some distinctive features: on the demand side, consumers have differentiated tastes with respect to these three products; on the supply side, we explicitly take into account the IP costs that GM food would impose on other goods in the equilibrium. For organic food, we model quality enhancement as resulting from additional efforts supplied by producers. We endogenise the reward to these efforts and the price of land. The calibrated model is solved for equilibrium prices, quantities and welfare changes, and these simulation results are supplemented by some sensitivity analyses.

The results show that the introduction of GM products in this context reduces welfare, as well as both consumers' and producers' surplus. This conclusion differs from those of existing empirical studies, which have found a positive welfare impact of the new GM technology (e.g. Falck-Zepeda et al., 2000; Moschini et al., 2000; Demont and Tollens, 2004), but it is in keeping with the analyses of Lapan and Moschini (2004), Fulton and Giannakas (2004), and Sobolevsky et al. (2005). There are at least four reasons for that. First, here we explicitly allow for differentiated consumer preferences, specifically for some consumers to have a preference for non-GM products. Second, in this model, we have also assumed that it is costlier to provide non-GM products in the post-GM situation because of the need for IP activities. Both these features, ignored by the aforementioned studies, appear quite 
relevant, and their explicit consideration should improve our assessment of the economic impact of the new GM technology. Third, in this study, we have also neglected the ex post returns to the providers of the GM innovation, for reasons discussed earlier. ${ }^{19}$ Finally, our analysis explicitly models the multi-market effects of GM adoption and specifically accounts for the endogeneity of the returns to agriculture's foremost fixed input, land.

An important attribute of the GM product innovation effects highlighted by our model is the distinction between the total and marginal impact of GM innovation adoption. Such a distinction derives from the fact that we have modelled a market failure associated with the per se introduction of the (otherwise efficiencyenhancing) innovation. The introduction of GM products entails some drastic adjustments for the agricultural sector, and hitherto unnecessary segregation activities (a real resource cost) are now necessary, which tends to decrease aggregate welfare. But given that GM products are introduced, ceteris paribus, it may be desirable to have a larger rather than smaller diffusion of the product. For instance, the labelling and traceability requirements of GM products, which act as a disincentive to the (marginal) adoption of GM products, here further decrease aggregate welfare.

Another conclusion of our analysis is that the introduction of GM products actually benefits the producers of organic food. Such a conclusion, of course, is bound to depend on possible differences in segregation costs for the two non-GM products. Insisting on a zero tolerance level for the adventitious presence of GM content in organic food, for example, presumably requires costlier segregation activities, and that will hurt organic producers. We also show that the new EU labelling and traceability requirements do decrease the market share of GM food and hurt the overall returns to farmers, but actually have a slightly positive impact on the welfare of consumers (production costs decrease because of lower land rents).

One of the main contributions of this article is the derivation of a model that allows for a differentiated food demand, induced by the innovation itself, and to show that such a differentiated demand structure can be embedded in a standard equilibrium model of the agricultural sector that is suitable for welfare analysis. The new GM product can be thought of as existing before the innovation, but with zero production because it is too costly (given demand). Innovation reduces the unit production cost for the new product below the choke price and results in positive production of the GM product. Given the competitive structure of the model and without additional effects, such an efficiency-enhancing innovation would increase aggregate welfare. Indeed, we verify that eventuality in the benchmark reported in the first column of Table 3. But, in our setting, the introduction of the new GM product brings about the need for segregation of non-GM products. As noted by Moschini and Lapan (2005), this external effect essentially

\footnotetext{
${ }^{19}$ If we were interested in evaluating the ex post welfare effects of a given (available) innovation, it would possibly be desirable to account for such returns to the providers of the innovation, and that could clearly change the overall welfare picture. In contrast, if the focus is on EU welfare, a relevant observation is that the current GM traits are mostly owned by companies located outside the EU. Indeed, some have suggested this fact may provide an important political-economy explanation for the dramatically different treatment so far accorded to these products in the United States and the EU (Graff and Zilberman, 2004).
} 
induces a non-convexity in the aggregate production set (the link between externalities and non-convexities is well known; see, e.g. Mas-Colell et al., 1995, Chap. 11). Because of this externality, the conditions for the first welfare theorem fail, and we can no longer presume that the competitive equilibrium achieves a first-best outcome. In fact, the results reported in this article illustrate the potential for welfare to decrease because of the innovation. Although qualitatively interesting, the actual magnitude of the market and welfare impacts uncovered obviously depends on the necessarily simplified structure of the model and on the parametric calibration that was implemented. The sensitivity analysis carried out provides some comfort as to the robustness of the results presented, but much scope remains for future work devoted to a more exact account of the many (sometimes unexpected) impacts that modern biotechnology has on the agricultural sector.

\section{References}

Boccaletti, S. and Moro, D. 'Consumer willingness-to-pay for GM food products in Italy', AgBioForum, Vol. 3, (2000) pp. 259-267.

Brookes, G. The Co-existence of GM and non-GM Arable Crops in the EU: Economic and Market Considerations (Ravello, Italy: July ICABR Conference, 2004).

Buckwell, A., Brookes, G. and Bradley, D. Economics of IP for Genetically Modified Crops (London: December Report for FBCI, 1999).

Bullock, D. and Nitsi, E. 'GMO adoption and private cost savings: GR soybeans and Bt corn', in G. C. Nelson (ed.) Genetically Modified Organisms in Agriculture: Economics and Politics, (Academic Press, London, 2001), pp. 47-58.

Commission of the European Communities. Commission Recommendation on Guidelines for the Development of National Strategies and Best Practices to Ensure the Co-existence of Genetically Modified Crops with Conventional and Organic Farming (Brussels: Press Release, IP/03/1056, 22 July, 2003).

Demont, M. and Tollens, E. 'Ex ante welfare effects of agricultural biotechnology in the European Union: The case of transgenic herbicide tolerant sugarbeet', in R. E. Evenson and V. Santaniello (eds), The Regulation of Agricultural Biotechnology (Wallingford, UK: CABI Publishing, 2004).

Demont, M., Wesseler, J. and Tollens, E. 'Biodiversity versus transgenic sugar beets: The one Euro question', European Review of Agricultural Economics, Vol. 31, (2004) pp. 1-18.

Desquilbet, M. and Bullock, D. S. Who Pays for the Cost of Non-GMO Segregation and Identity Preservation? (Tucson, AZ: Paper presented at the IATRC Meeting, 2001).

EU Directorate General for Agriculture. Agriculture in the European Union-Statistical and Economic Information 2002, (http://europa.eu.int/comm/agriculture/agrista/2002/table_en/ en31.htm. March; 2003).

European Union. GMOs: Commission Publishes Recommendations to Ensure Co-existence of GM and Non-GM Crops (IP/03/1096, Press release, 23 July 2003).

European Union. Question and Answers on the Regulation of GMOs in the EU (Brussels, MEMO/04/85, 15 April, 2004).

European Commission. Scenarios for Co-Existence of Genetically Modified, Conventional and Organic Crops in European Agriculture (http://www.jrc.cec.eu.int/download/GMCrops_ coexistence.pdf; Joint Research Centre, 2002).

Fishler, F. Quality Matters: A New Focus for Agricultural Policy, (Brussels: Speech delivered at the CIAA - European Food Summit, 12 April, 2002).

Falck-Zepeda, J. B., Traxler, G. and Nelson, R. G. 'Surplus distribution from the introduction of a biotechnology innovation', American Journal of Agricultural Economics, Vol. 82, (2000) pp. 360-369. 
Fulton, M. and Giannakas, K. 'Inserting GM products into the food chain: The market and welfare effects of different labeling and regulatory regimes', American Journal of Agricultural Economics, Vol. 86, (2004) pp. 42-60.

Giannakas, K. and Yiannaka, A. Agricultural Biotechnology and Organic Agriculture: National Organic Standards, Labeling and Second-Generation of GM Products, (Montreal, Canada; Paper Presented at the AAEA Annual Meeting, July, 2003).

Golan, E., Kuchler, F., Mitchell, L., Greene, C. and Jessup, A. Economics of Food Labeling (ERS, U.S. Department of Agriculture, AER No. 793, December, 2000).

Gracia A., Gil, J. M. and Angulo, A. M. 'Spanish food demand: A dynamic approach', Applied Economics, Vol. 30, (1998) pp. 1399-1405.

Graff, G. D. and Zilberman, D. Explaining Europe's Resistance to Agricultural Biotechnology (UPDATE Agricultural and Resource Economics, University of California Giannini Foundation, May/June, 2004).

Hamm, U., Gronefeld, F. and Halpin, D. Analysis of the European Market for Organic Food, OMIaRD, Vol. 1, (Aberystwyth, School of Management and Business, University of Wales, 2002).

James, C. Global Review of Commercialized Transgenic Crops: 2004 Preview, (Ithaca, NY: ISAAA Brief No. 32, 2005).

Lapan, H. and Moschini, G. 'Innovation and trade with endogenous market failure: The case of genetically modified products', American Journal of Agricultural Economics, Vol. 86(3), (2004) pp. 630-644.

Lin, W., Chambers, W. and Harwood, J. Biotechnology: U.S. Grain Handlers Look Ahead, (Washington, D.C.: Agricultural Outlook, U.S. Department of Agriculture, April, 2000).

Marra, M., Pardey, P. and Alston, J. 'The payoffs of transgenic field crops: An assessment of the evidence', AgBioForum, Vol. 5, (2002) pp. 43-50.

Mas-Colell, A., Whinston, M. D. and Green, J. R. Microeconomic Theory, (New York: Oxford University Press, 1995).

Moon, W. and Balasubramanian, S. K. 'Public perceptions and willingness-to-pay a premium for non-GM foods in the US and UK', AgBioForum, Vol. 4, (2001) pp. 221-231.

Moschini, G. 'The semiflexible almost ideal demand system', European Economic Review, Vol. 42, (1998) pp. 349-364.

Moschini, G. and Lapan, H. 'Intellectual property rights and the welfare effects of agricultural R\&D', American Journal of Agricultural Economics, Vol. 79, (1997) pp. 12291242 .

Moschini, G. and Lapan, H. 'Labeling regulations and segregation of first- and secondgeneration GM products: Innovation incentives and welfare effects', in R. E. Just, J. Alston and D. Zilberman (eds), The Economics of Regulation of Agricultural Biotechnologies (New York, NY: Springer, in press, 2005).

Moschini, G., Lapan, H. and Sobolevsky, A. 'Roundup ready soybeans and welfare effects in the soybean complex', Agribusiness, Vol. 16, (2000) pp. 33-55.

Mussa, M. and Rosen, S. 'Monopoly and product quality', Journal of Economics Theory, Vol. 18, (1978) pp. 301-317.

Noussair, C., Robin, S. and Ruffieux, B. 'Do consumers not care about biotech foods or do they just not read the labels?' Economics Letters, Vol. 75, (2002) pp. 47-53.

Noussair, C., Robin, S. and Ruffieux, B. 'Do consumers really refuse to buy genetically modified food?' Economic Journal, Vol. 114, (2004) pp. 102-120.

Qaim, M. and Traxler, G. 'Roundup ready soybeans in Argentina: Farm level and aggregate effects', Agricultural Economics, Vol. 32, (2005) pp. 73-86.

Qaim, M. and Zilberman, D. 'Yield effects of genetically modified crops in developing countries', Science, Vol. 299, (2003) pp. 900-902.

Sheldon, I. 'Regulation of biotechnology: Will we ever 'freely' trade GMOs?' European Review of Agricultural Economics, Vol. 29, (2002) pp. 155-176. 
Sobolevsky, A., Moschini, G. and Lapan, H. 'Genetically modified crops and product differentiation: Trade and welfare effects in the soybean complex', American Journal of Agricultural Economics, Vol. 87, (2005) pp. 621-644.

Tiffin, A. and Tiffin, R. 'Estimates of food demand elasticities for Great Britain: 1972-1994', Journal of Agricultural Economics, Vol. 50, (1999) pp. 140-147.

Tirole, J. The Theory of Industrial Organization (Cambridge, MA: The MIT Press, 1988). 


\section{Erratum}

Two typographical errors have inadvertently appeared in the following article:

Moschini, G., Bulut, H., and Cembalo, L. 'On the segregation of genetically modified, conventional and organic products in european agriculture: A multi-market equilibrium analysis', Journal of Agricultural Economics, Vol. 56 (3), (2005) pp. $347-372$

Specifically, equation (9), p. 354, should read:

$$
d_{b}\left(p_{Q}, p_{b}\right)=k(\lambda)^{-\lambda(1-\varepsilon)}(1-\lambda)^{\varepsilon+\lambda(1-\varepsilon)}\left(p_{Q}\right)^{\lambda(1-\varepsilon)}\left(p_{b}\right)^{-\varepsilon-\lambda(1-\varepsilon)},
$$

and equation (12), p. 354, should read:

$$
D_{b}\left(p_{n}, p_{g}, p_{b}\right)=d_{b}\left(p_{n}, p_{b}\right)(1-\phi)\left(\frac{p_{g}}{p_{n}}\right)+d_{b}\left(p_{g}, p_{b}\right)\left(A\left(p_{n}, p_{g}\right)+\phi\right)
$$

The Editor apologises for any inconvenience these errors may have caused. 